\title{
Perception of Linguistic Ambiguity
}

\author{
Dr. Mohammad Awwad \\ Assistant Professor, Lebanon
}

doi: 10.19044/esj.2017.v13n20p185 URL:http://dx.doi.org/10.19044/esj.2017.v13n20p185

\begin{abstract}
A qualitative-quantitative study was conducted on students preparing for their Master's degree in English, linguistic and literary branch, at the Lebanese University, the deanship, to investigate the participants' perception of ambiguity in language. Ambiguity in language is considered a problematic issue since it hinders precise language processing. Ambiguity leads to a confusion of ideas in the reader's mind, for the reader will struggle to decide on the precise meaning intended behind an utterance. This study presented a holistic view on EFL learners' perception of ambiguity. Via three questionnaires, the subjects' perception of ambiguity was tested on the recognition and production levels as well as sentential and textual levels. The results depicted that the subjects were unaware of ambiguous language, and at many times ambiguity hindered the subjects' ability to process language precisely. The research threw at some strategies that aid in disambiguating ambiguous language on the production level, and deciphering ambiguity on the interpretation level. Implications and recommendations for teachers, students, and curriculum designers were offered in the light of the study's findings.
\end{abstract}

Keywords: Ambiguity, Disambiguation, Language Processing

\section{Introduction}

The basis for a successful communication between individuals, according to language philosophers, has not remarkably evolved from the sixteenth century till our current era. Locke in 1698 as cited in Brown 1996 explicitly stated that "unless a man's words excite the same ideas in the hearer which he makes them stand for in speaking he does not speak intelligibly" (p. 6). This 'same idea' between the speaker and the listener referred to by Locke is obstructed by various variables; one of which is ambiguity in the mode of communication itself, that is to say, ambiguity in language. While the primary aim of language consists of transmitting information, in conveying a piece of knowledge from human A to human B, ambiguities seem to run contrary to that aim as they leave a message 
recipient with a less transparent and less usable kind of data” (p.1). Paget (1930) in Human Speech expresses the liability of words' ambiguity “each root word is naturally liable to bear many different meanings” (p.7), and 'those different meanings' are a direct cause for linguistic ambiguity. Therefore, when presenting the issue of language ambiguity, the researcher is shedding light on an impediment to language processing and an obstacle to smooth communication and here lies the topic's significance.

The term ambiguity, to Empson (2014), is associated with the word puzzling, or perplexing and perplexing indicates a form of unclarity in the communication process. It is noteworthy to mention that linguists pinpointed that ambiguity can be either intentional or unintentional. Intentional ambiguity is used at many instances by politicians and diplomats so the words uttered by the latter are free of any obligations. Moreover, intentional ambiguity can be used to create satire and add humor to the text. On the other hand, unintentional ambiguity, the subject of this study, is considered as a flaw of one's communication skills because it can be the root of misunderstanding.

The fact that ambiguity occurs on so many linguistic levels suggests that a far- reaching principle is needed to explain its origins and persistence. The existence of ambiguity in language is rendered as a puzzle for linguists, theorists, and educators who attempt hard to completely solve this riddle. The preliminary requisite for any solution is to diagnose the problem and to indicate its manifestations by precisely perceiving it. Consequently, before looking for solutions to disambiguate ambiguous language, any study must investigate the perception of learners to what ambiguity is, what it is not, and what falls under linguistic ambiguity. In the light of the above, this study shed light on the perception of ambiguity and its types which are responsible for hindering students' interpretation of the English language and the subsequent obstacles in language generation; this may sharpen our vigilance, as teachers and learners, for ambiguous words and phrases and aid us to decipher ambiguous statements and develop better potency in processing language.

\section{Purpose of the Study}

It came to the researcher attention that English major students at the Lebanese University, the Deanship, are unaware of linguistic ambiguity and its impact on language processing. Therefore, the purpose of the study is to scrutinize learners' awareness of ambiguity; eventually cues for deciphering ambiguous sentences, words and structures will be induced. All this converges in an attempt to disambiguate English language structures, and thus provide learners with a better language processing outcome and enhance teachers with a more facile and lucid teaching task. 


\section{Research Questions}

The research aims at investigating the perception of ambiguity in language, and thus addresses the following questions:

1. What does linguistic ambiguity refer to?

2. What type of ambiguity do English major students seem to struggle most at?

3. What are the methods that can be implemented to disambiguate English sentences?

\section{Hypotheses:}

Based on the research questions, the following hypotheses are formulated, and the study seeks to examine the significance of four hypotheses:

1. Semantic ambiguity is harder for students in processing language than is syntactic ambiguity.

2. Linguistics major students achieve a higher level of interpreting ambiguous sentences than do their peers in the literary branch.

3. Students with teaching experience process linguistic ambiguity better than those with no experience.

4. Students who know a language, other than their native, and English perform better in deciphering language categorized with ambiguity than their bilingual peers.

\section{Statement of the Problem}

The topic of ambiguity in language is a debatable one: does ambiguity serve language by the enrichment it gives to the text and by making such texts more flexible? Or does it impose confusion and thus mislead the reader through the meanings? On one hand, ambiguity may enrich texts, convey meanings without having to bluntly state them, and can intentionally add humor where needed; however, ambiguity may account for many misinterpretations between the speaker or the writer and the listener or the reader. Cleverly manipulated use of language ambiguity in newspapers is liable to catch the readers' attention (Ferreira, 1996). For example, "Iraqi heads seek arms” (Ferreira 1996, p.35) is a captivating newspaper title due to the exploitation of ambiguity. Head can be interpreted as chief or as a body part; arms can be referred to either weapons or body parts. Besides, linguists who argue for ambiguity as an attribute that enriches language believe that ambiguity is the savior for politicians who can, through the appropriate use of ambiguity, flee themselves from being convicted of any promises. Hurford and Brendon (1983) gave the following advice to politicians: "through the use of ambiguity and question dodging, let a politician say not a single word about his principles or his creed, let him say nothing, promise nothing. Let 
nobody ever extract from him a single word about what he thinks now, or what he will do here after” (p.155). Despite all its appealing usages, many linguists still render ambiguity as an impediment obstructing language processing for learners and as a mystery to be deciphered if mastery of a language shall take place specially that "language learning is an extremely exacting endeavor” (Donlevy, 2005, p.7). Ambiguity, as Klepousniotou (2002) explains, leads to a confusion of ideas in the reader's mind, for the reader will struggle to decide on the precise meaning intended behind an utterance. Cushing (1997), furthermore, argues that ambiguity can result in an imprecise or rather wrong conclusions formulated by the listener in the speaker-hearer communicative situation which can lead to a communication breakdown between the speaker - hearer or the writer- reader.

This study sheds light on ambiguity as an obstacle to language processing. A speaker might be lost during the reading process; a speaker might be lost while listening; a writer might also feel at a loss while responding to someone's ambiguous writing. The rationale behind all such issues is ambiguity. From here, it becomes explicit that both learners and teachers must understand the concept of ambiguity, its types, and ways to disambiguate language in an aim to minimize impediments that stampede language processing. An analytical study demonstrating and clarifying ambiguity types and ways of deciphering them will abolish misunderstanding between encoders and decoders. Eventually, "ambiguity plays a role in our cognitive understanding and interpretative abilities, so studying this phenomenon and examining how to resolve it can give us an insight in both thought and interpretation” (Dunbar, 2001, p.12).

\section{Literature Review}

\section{Definition of Ambiguity}

In 1930, William Empson gave a detailed description of seven types of ambiguity in literature. Empson further revised his book and modified some concepts in the books' second edition in 2014. According to Empson (1930), ambiguity can be best defined as "any verbal nuance, however slight, which adds some nuance to the direct statement of the prose (p. 1). In the second edition of the book, Empson (2014) restated the definition and added "which gives room for alternative reactions to the same piece of language" (p. 5). According to Empson, the fundamental situation, to term a word or a grammatical structure as ambiguous or not, is if the latter can be effective in several ways. 


\section{Types of Ambiguity}

Through investigating related studies in linguistic ambiguity, the researcher found out that ambiguity in language can come under four broad classes: lexical, syntactic, semantic, and pragmatic ambiguity.

Lexical ambiguity takes place when a single word has more than one meaning, or when a word can be interpreted in more than one sense Dayal (2004). Syntactic ambiguity occurs when a given sequence of words can be given more than one grammatical structure, and each structure gives a different meaning (Zelta, 2014). Semantic ambiguity occurs when a sentence has more than one way of reading it within its context although it contains no lexical or structural ambiguity. Semantic ambiguity can be due to the logical form or sense of a word or due to scope quantifiers that is when there are two ways for interpreting the sentence even if the syntactical and lexical structures are the same Cruse (1986). Pragmatic ambiguity occurs when a sentence has several meanings in the context in which it is uttered. This can be classified as ambiguity in speech acts, ambiguity in presuppositions, and referential ambiguity Zelta (2014).

\section{Methodology}

\section{Research Design}

This research is a descriptive study, which is a type of nonexperimental research that investigates the perception of sixty Lebanese University Students, preparing for their Master's degree in English, of ambiguity in language.

The design follows a mixed qualitative-quantitative method. It is qualitative since qualitative studies seek to understand people's perception, attitude, and motivation, and it is quantitative because the data has been represented with numbers and graphs (Salkind 2012).

\section{Subjects}

Sixty students preparing for their Master's degree in English, linguistics and literary branches, at the Deanship of the Lebanese University, participated in the study. The subjects' ages ranged between twenty-one and forty-nine. Table 1 presents the subjects' demographic information:

Table 1: Subjects' Demographic Information

\begin{tabular}{|c|c|c|c|c|c|c|c|c|c|c|c|}
\hline \multicolumn{2}{|c|}{ Major } & \multicolumn{2}{|c|}{ Gender } & \multicolumn{2}{l|}{$\begin{array}{l}\text { Native } \\
\text { language }\end{array}$} & \multicolumn{2}{l|}{$\begin{array}{l}\text { Language spoken } \\
\text { other than English }\end{array}$} & \multicolumn{2}{|l|}{$\begin{array}{l}\text { Years of } \\
\text { Teaching } \\
\text { experience }\end{array}$} \\
\hline $\begin{array}{l}\text { Linguist } \\
\text { ics }\end{array}$ & $\begin{array}{l}\text { Literat } \\
\text { ure }\end{array}$ & $\begin{array}{l}\text { Fema } \\
\text { le }\end{array}$ & $\begin{array}{l}\text { Ma } \\
\text { le }\end{array}$ & $\begin{array}{l}\text { Arab } \\
\text { ic }\end{array}$ & $\begin{array}{l}\text { Armeni } \\
\text { an }\end{array}$ & $\begin{array}{l}\text { Fren } \\
\text { ch }\end{array}$ & $\begin{array}{l}\text { Germ } \\
\text { an }\end{array}$ & $\begin{array}{l}\text { Spani } \\
\text { sh }\end{array}$ & $\begin{array}{l}0 \\
- \\
3\end{array}$ & $\begin{array}{l}5 \\
\text { yrs } \\
+\end{array}$ \\
\hline 8 & 32 & 56 & 4 & 57 & 3 & 30 & 1 & 2 & $\begin{array}{l}2 \\
7\end{array}$ & $\begin{array}{l}1 \\
5\end{array}$ \\
\hline
\end{tabular}




\section{Instruments}

Three questionnaires were passed to the participants to test their perception of linguistic ambiguity. The first questionnaire (Appendix A) aimed at investigating the recognition level of ambiguity perception for the participants (sentence level); the second questionnaire (Appendix B) aimed at investigating the production level of ambiguity perception for the participants (sentence level); the third questionnaire (Appendix C) aimed at investigating the production level of ambiguity perception for the participants (textual level). The questions used in the survey are collected from eclectic examples used by linguists as illustrations on different types of ambiguity in language including (Atlas, 1989), (Kent,1997), (Cann, 1993), (Crystal, 1998), (Dayal, 2004), (Empson,2014), (Ferreira, 1996), (Hirst, 1987), (Pehar,2001), (Zelta, 2014).

\section{Procedure}

Thirty minutes were allocated to questionnaire one, sixty minutes to questionnaire two, and thirty minutes to questionnaire three. The students were asked to fill in the demographic information, and were instructed to identify the ambiguous part in the first questionnaire, to write all possible interpretations in the second questionnaire, and to interpret the ambiguity in the given texts in the third questionnaire. The study took place in spring 2015- 2016.

\section{Discussion and Analysis}

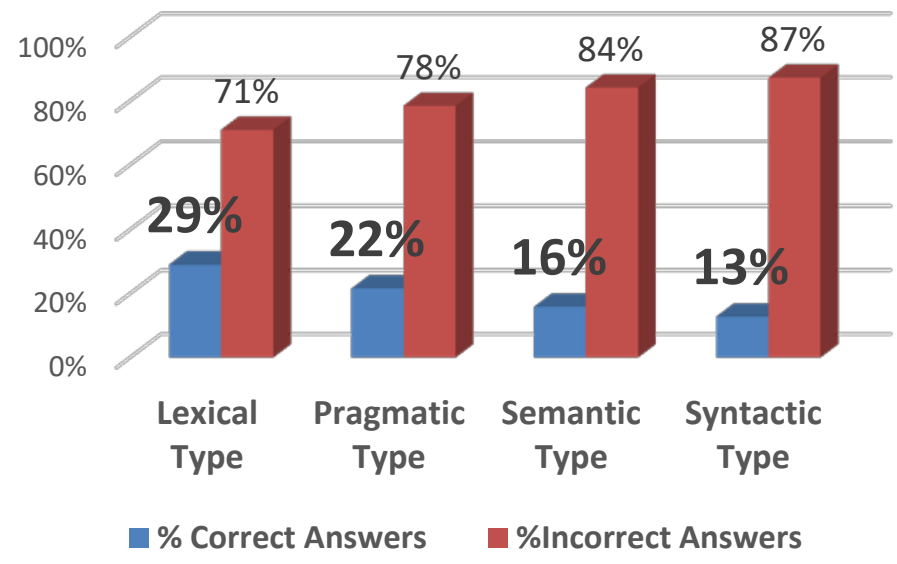

Figure 1: Percentage Correct Answers in Different Ambiguity Types

The correct and incorrect responses of each ambiguity type are presented in Figure 4. The researcher combined responses from questionnaires 1, 2, and 3 according to their types. Questionnaire 1 tested the 
recognition level of ambiguity perception (sentence level), and it was divided as follows: items 1, 2, 3, 4, and 5 (syntactic ambiguity); items 6, 7, 8, 9, and 10 (lexical ambiguity); items 11,12,13,14, and 15 (semantic ambiguity: scope), 16,17,18,19, and 20 (semantic ambiguity transformational).

Questionnaire 2 tested the production (sentence level) where students were asked to write all possible interpretations of the sentences; sentences were marked as perceived only when the subjects were able to identify at least two different interpretations since this is what marks linguistic ambiguity. Items 1, 2, and 3 are syntactic (attachment), 4,5, and 6 syntactic (analytical), 7,8, and 9 syntactic (coordination), 10, 11, and 12 syntactic (ellipsis); items 13,14,15,16, and 17 (lexical); items 18,19,20,21, and 22 semantic (transformational); items 23,24,25,26, and 27 semantic (scope); items 28,29,30, 31, 32 pragmatic (referential); items 33,34,35,36,37 pragmatic (presuppositions); items 38,39,40 pragmatic (speech acts). More examples demonstrated the syntactical type than the lexical type since syntactic ambiguity has many sub divisions in contrast with lexical ambiguity.

Questionnaire 3 tested recognition and production of ambiguity (textual level). Items $1 \& 2$ demonstrated lexical ambiguity, item 3 syntactic ambiguity, item 4 semantic ambiguity, \& item 5 pragmatic ambiguity. The results show that students struggled most at processing syntactic ambiguity $87 \%$ wrong answers, semantic ambiguity (84\% wrong answers) comes second, pragmatic ambiguity $78 \%$ comes third, and lastly lexical ambiguity $71 \%$; this answers the second research question of the study. The above finding contradicts that of Karp (1992) and that of Brause (1977) which claim that syntactical ambiguity is less challenging than lexical ambiguity to learners of English as a second language. It is in harmony with the study of Kusumawati (2001) and that of Chele (2015) which point out that structural ambiguity is harder to process for English second language learners than is lexical ambiguity.

The results of syntactical ambiguity (attachment type) reinforce Khawalda and AL Sadat's finding that learners tend to attach the modifier to the NP rather than the VP. As for the scope ambiguity, previous studies that claimed that the scope of the intensifier dominated the scope of the article as in the example: all linguists prefer a theory was interpreted as each linguist preferred a different theory than all preferred one theory cannot be asserted nor negated since scope ambiguity items were not answered by $93.3 \%$ of the participants, and the remaining four respondents did not indicate precise answers as to ambiguity position in the sentences. 


\section{Analysis of Data}

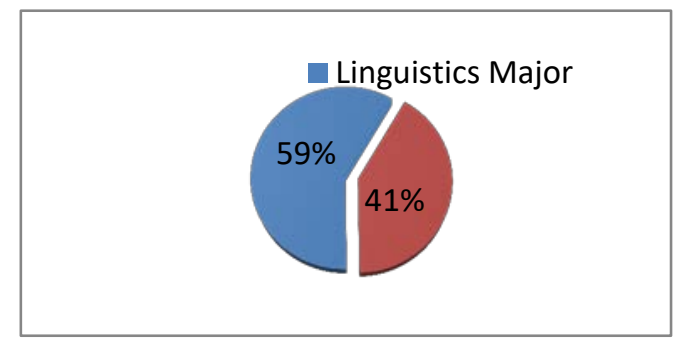

Figure 2: Correct Answers Distribution According to Majors

Figure 2 shows that $59 \%$ of the correct answers were given by linguistic major students and $41 \%$ by the literature major students.

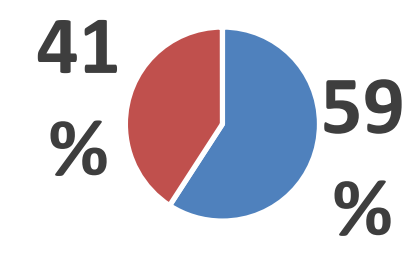

- Trilingual Bilingual

Figure 3: Correct Answer Distribution based on Multilinguality

Fifty-nine percent of the correct responses were given by trilingual students, and $41 \%$ by bilinguals which hints that trilingual performance exceeded their bilingual peers. Figure 7, below, compares the performance of bilingual and trilingual students in each type of ambiguity. 


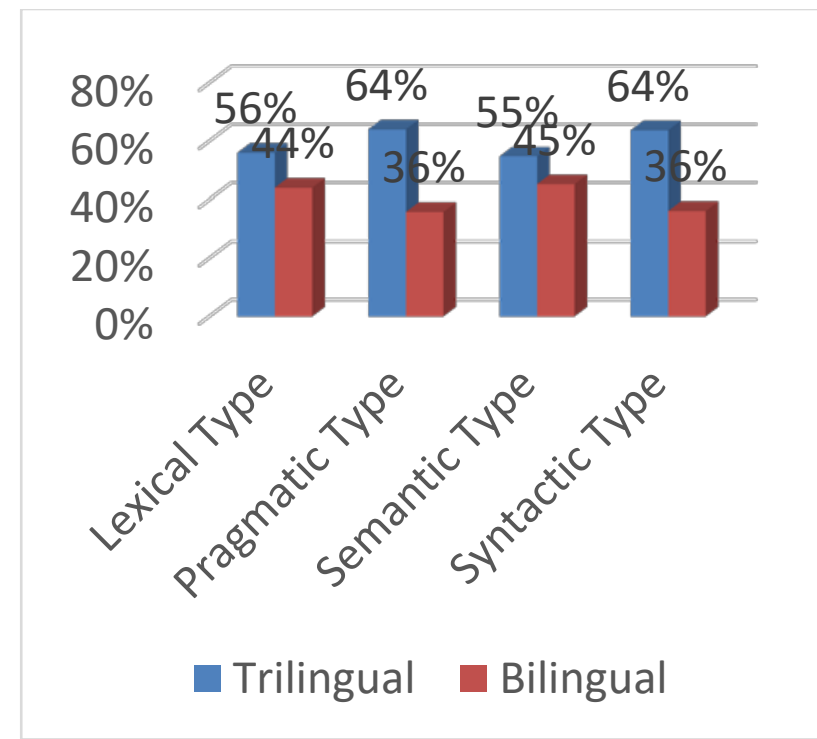

Figure 4: Correct Answers Distribution according to Multilinguism Per Type

Figure 4 presents the percentage of correct ambiguity items as classified per types on the two study groups: bilinguals and trilinguals. Trilinguals performed best in pragmatic and syntactic ambiguity, while bilinguals performed best in semantic ambiguity; however, trilinguals performed better than bilinguals in all ambiguity type questions.

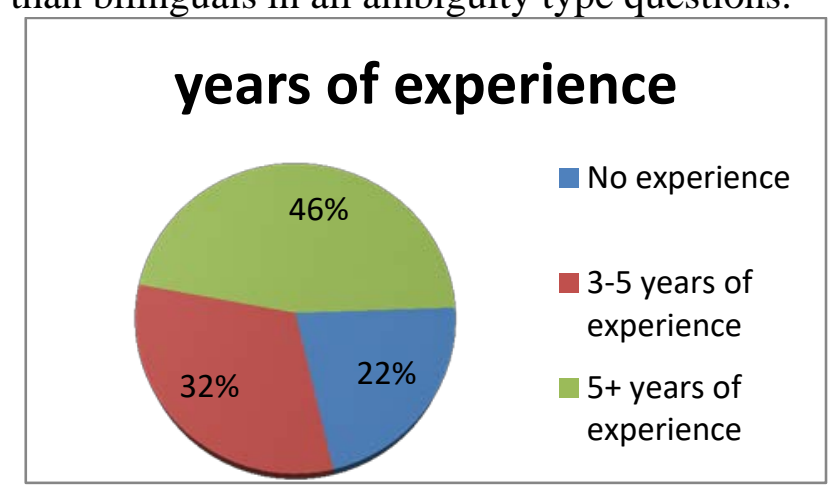

Figure 5: Correct Answer Distribution on Years of Experience

Figure 5 shows the percentage of correct answers as distributed by years of experience. Forty-six percent of the correct answers were given by subjects with more than five years teaching experience; thirty two percent of correct responses were given by teachers with 3-5 years of teaching experience; twenty- two percent of correct answers were given by subjects having no teaching experience. 


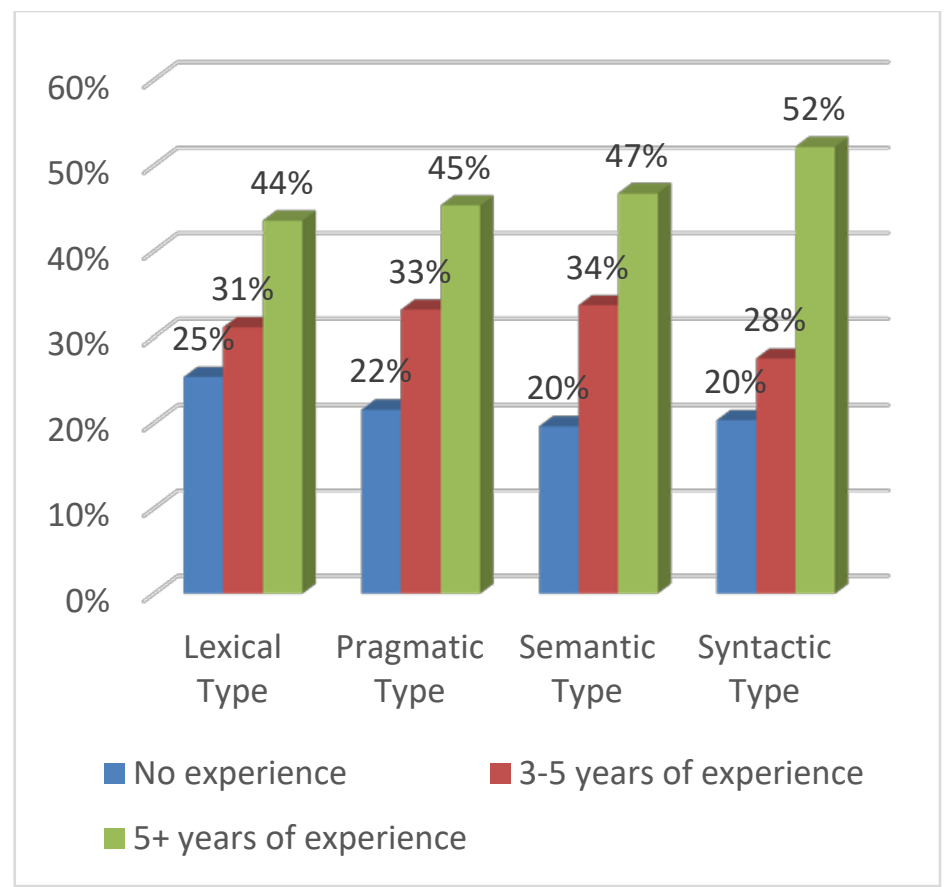

Figure 6: Correct Answers Distribution According to Experience (Years) Per Type

Figure 6 presents the percentage of correct answers to each ambiguity type distributed among the group of the study (experience variable). Subjects with no experience performed best on the lexical type; subjects with 3-5 years of teaching experience performed best on semantic type; and subjects with more than 5 years teaching experience performed best on the syntactic type.

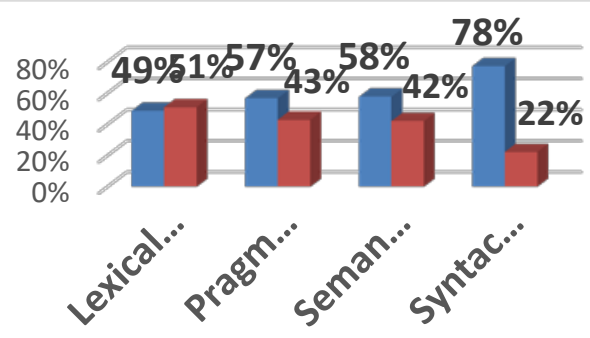

- Linguistics Major $\quad$ Literature Major

Figure7: Correct Answers according to Majors Per Ambiguity Type

Figure 7 shows the percentage difference between linguistic and literary major participants regarding performance on each ambiguity type. It is evident that linguistics major students outperformed literary branch 
students regarding all types of ambiguity except the lexical type (49\% for literary versus $51 \%$ for the linguistic branch). table 2 .

The mean and standard deviation on each ambiguity type is given in

Table 2: Correct Answers Average and Standard Deviation

\begin{tabular}{|l|l|l|}
\hline & Mean & Standard Deviation \\
\hline Lexical Type & 17.42 & 16.71 \\
\hline Pragmatic Type & 12.93 & 8.26 \\
\hline Semantic Type & 9.48 & 11.06 \\
\hline Syntactic Type & 7.67 & 6.42 \\
\hline Total & 11.18 & 11.11 \\
\hline
\end{tabular}

On average, students correctly answered approximately 17 questions of the lexical type, 13 of the pragmatic type, 9 of the semantic type and 8 of the syntactic type. The standard deviation denotes a minimum-to-maximum number of correct answers. For the lexical type, the correct answers ranged from 1-to-33. For the pragmatic type, the correct answers ranged between 6to-20; and 2-to-20 for the semantic type and 1-to-13 for the syntactic type. As for all the types, students answered 11 correct answers on average.

Based on the statistics, the following can be inferred regarding the study's hypotheses:

\section{Hypothesis 1:}

Hypothesis 1 is rejected in the t-test, where students scored higher in the semantic questions opposed to the syntactic one. The difference of means between both is 1.81 and it is a significant finding where the p-value, which equals 0.033 , is less than a 0.05 significance level (alpha) on a 95\% confidence level.

\section{Hypothesis 2:}

Linguistics major students did perform better than literature major students with a mean difference of 1.96. However, the finding is not significant where p-value $0.216>$ alpha 0.05 . Therefore, we suggest further research to test the significance.

\section{Hypothesis 3:}

There is a statistically significant difference between the group means with a p-value: 0.025 < alpha: 0.05 at a 95\% confidence level. Students with teaching experience performed better than students without experience with a mean difference of 2.59. Hypothesis 3 is significantly accepted as the pvalue $0.0178<$ alpha 0.05 at a $95 \%$ confidence level. 


\section{Hypothesis 4:}

At a significance of 0.05 (95\% confidence level), the difference between the means of trilingual and bilingual students is significant with a pvalue $=0.041<0.05$.

Hypothesis 4 is accepted as trilingual students' performance exceeded their bilingual peers with a mean difference of 3.61. This finding is significant with a p-value 0.0407 < alpha 0.05 on 95\% confidence level.

\section{Conclusion}

The study revealed that ambiguity in language is best defined as the presence of two or more distinct meanings in a sentence whether those two interpretations are due to lexical, semantic, syntactic, or pragmatic inflictions; and nothing in the sentence favors a meaning on the other. Both are semantically and syntactically perfectly logical. "A sentence is considered ambiguous when a sequence of words can be structured in alternative ways that are consistent with the syntax of the language or when a given lexical item has more than one semantic interpretation” (Cann 1993, p.8).

Moreover, the results of the study show that students at the Lebanese University struggled most at processing syntactic ambiguity 87\% wrong answers; semantic ambiguity (84\% wrong answers) comes second; pragmatic ambiguity $78 \%$ comes third; and lastly lexical ambiguity $71 \%$.. It is noteworthy to mention that subjects of this study have studied English for at least 10 years (since elementary level) which may be a reason why the finding contradicts that of Karp (1992) and that of Brause (1977). The subjects in the afore mentioned studies have started to study English at a later stage of education which may be a reason why lexical ambiguity was the harder for them to process than was structural ambiguity; their vocabulary bank is considered relatively poorer compared to that of our subjects who probably encountered different word meanings throughout their learning progress, and this may be a reason why lexical ambiguity was the easiest for our subjects to process with a $29 \%$ correct answers. Though this number is also considered very low, it is higher than $13 \%$ correct responses for syntactic ambiguity part, 16\% correct responses for semantic ambiguity part, and 22\% correct responses for pragmatic ambiguity part.

\section{Recommendations}

\section{Disambiguating Ambiguity}

\section{Context Clues}

Context clues are the main source of information that aid the reader in deciphering ambiguous words or phrases (Cunningham 1983). In general, word sense can depend not only on the full context, but also on local cues as 
the meaning of nearby cues, as the meaning of nearby words. The semantic association between one sense of the ambiguous word and the nearby words is the key for disambiguation. For instance, in the sentence the dog's bark woke me up, the words woke me up make it definite that bark here is not the surface of a tree. As Hayes (1977) puts it "an association between a sense of an ambiguous word and the context surrounding a use of that word is strong evidence that the interpretation of that word should come through that sense" (p.43). For example, in a context of dinner, pitcher is more highly to be a container of liquid, than to be a thrower of a ball.

\section{Syntactical Restrictions}

Syntactic ambiguity is best resolved when semantic constraints are applied to the sentences; however, many times fillers, as what follows the ambiguous word, are a good source of disambiguation (Fraizer, 1983). In the examples below:

a. Ross played with his toys.

b. Ross played his guitar.

The music making sense in the verb play in example $b$ requires an object while the recreation or game playing sense in the verb play in example $a$ requires a preposition. The filler be it an object or a preposition disambiguates the ambiguous sense of the verb play.

Therefore, the syntactic context or grammatical structure of words plays an important role in the resolution of both lexical and syntactic ambiguity.

\section{Minimal Attachment}

Kimball (1975) and Fraizer (1983) consider that in order to resolve ambiguity caused by the possibility of more than one structural parsing, the interpretation which creates the structure with the fewest nodes must be adopted. This is referred to as the principle of minimal attachment. In sentences of prepositional phrases, where the prepositional phrase (PP) can be either attached to the verb (VP) or to the noun (NP), the pp should be first attached to the verb since this attachment imposes fewer nodes than if attached to the noun; however, only if the VP attachment makes no sense, the NP attachment should be considered. In the example, I saw a man with the binoculars, the pp with the binoculars will be attached to the verb saw and not noun man; however the burglar blew open the safe with the diamonds, the pp with the diamonds cannot be attached to the verb so a nonminimal noun attachment is necessary: it is the safe with the jewels and not the open with the jewels. Another example is the final adverb, again, in I told her to run again: again can be attached to told or run but is preferably attached to the lower verb run according to Kimball. Kimball also noted that 
non minimal attachments took significantly more time than did minimal attachment in previously conducted studies

Relative clauses can be dominated by the first NP or the second NP. For example, the driver of the manager who lived there died can be perceived as the manager who lived there, or the driver who lived there with a preference to closest NP attachment that is the manager who lived there according to Cuetos and Mitchell (1988).

\section{Semantical Constraints}

Concept A can be associated with concept B in a certain mode only if $\mathrm{A}$ and $\mathrm{B}$ have special features. In the example, the bat ate its dinner, the subject of ate is animate; therefore, bat means flying mammal and not wooden club, while in the example, the broken bat lay on the ground, the adjective broken modifies inanimate objects, so bat here is a wooden club (Fraizer,1983).

\section{Recency Rule}

In anaphora, the referent is the most recently mentioned object of correct gender and number. Lappin and Leasse (1994) consider that if there are two or more candidate antecedents for an anaphor, the closest to the anaphor must be chosen. In the example, the policemen arrested the demonstrators because they were violent: "demonstrators" is nearer to they than are the policemen; so they is taken to refer to demonstrators, not to the policemen.

\section{Parallel Structure}

It is more likely, according to (Fraizer,1983), that parallel structure is employed in sentences with ambiguous referents. For example, John met Mike and he asked him to dinner, he refers to John; him refers to Mike.

\section{Recommendations for Future Researches}

The study can issue certain recommendations on future researches to be conducted on the topic of linguistic ambiguity. First, it was noted that lexical ambiguity was the easiest for the subjects to process in this study; this finding contrasts with previous studies of Karp (1992) and Brause (1977). The reason may be that the subjects of this study have acquired L2 at a very early age which might have enriched their vocabulary acquisition. Further research on the effect of early acquisition of L2 in resolving ambiguity, and the difference between L1 and L2 perception of ambiguity (recognition and perception) level is recommended. Second, an experimental study of teaching students different ambiguity types and exposing them to congruent ambiguous texts and sentences to scrutinize if their performance varies is 
also highly suggested for future research. Third, a correlational study between one's ability to perceive language ambiguity and to process comprehension passages is also advocated for future researches.

\section{References:}

1. Brause, R. (1977). Developmental aspects of the ability to understand semantic ambiguity, with Implications for teachers. Research in the teaching of English, vol. 11(1), 39-48. Retrieved from http: //www.jstor.org/stable 40170815

2. Brien, C., and Sabourin, L. (2012). Second language effects on ambiguity resolution in the first language. EUROSLA Yearbook, 12(1), 191-217. Retrieved from http://www.ingentaconnect.com/content/jbp/eusy/2012/00000012/00 000001/art00010

3. Brown, G. (1996). Speakers, listeners and communication: Explorations in discourse analysis. London: Cambridge University press.

4. Cann, R. (1993). Formal Semantics: an introduction. Cambridge: Cambridge University Press

5. Chele, M. (2015). The perception of Ambiguity by English L2 Speakers. Retrieved from https://www.lap-publishing.com/.../theperception-of-ambiguity-by-english

6. Cruse, D. (1986). Lexical Semantics. Introducing lexical relations. Cambridge: Cambridge University Press.

7. Crystal, D. (1998). A dictionary of linguistics and phonetics $6^{\text {th }}$ Edition 14-17.Retrieved from http://onlinelibrary.wiley.com

8. Cuetos, F., and Mitchell, D. C. (1988). Cross-linguistic differences in parsing: Restrictions on the use of the Late Closure strategy in Spanish. Cognition, 30(1), 73-105. Retrieved from http://www.sciencedirect.com/science/article/pii/0010027788900042

9. Cunningham, L. (1983). Verb Frame Preferences. Natural Language Processing. Cambridge: Cambridge University Press.

10. Cushing, S. (1997). Fatal Words Communication Clashes and Aircraft Crashes. Chicago: University of Chicago Press.

11. Dayal, V. (2004). The universal force of free choice any linguistic variation yearbook 4: 15-40. Retrieved from http//www.ingentaconnect.com

12. Dictionary, O. E. (2000). Oxford: Oxford university press.

13. Dictionary, C. E. (2003). Complete and unabridged. New York: HarperCollins Publishers.

14. Donlevy, C. (2005). A Human Response to Ambiguity: A Psycholinguistic 
https://www.cs.tcd.ie/undergraduate/computer-sciencelanguage/bacsll_web/donlevyc0405.pdf

15. Dunbar, G. (2001). Towards a cognitive analysis, ambiguity, and vagueness, Cognitive Linguistics,12(1), 1-14. Retrieved from

16. http://www.degruyter.com/view/j/cogl.2001.12.issue1/cogl.12.1.1/cogl.12.1.1.xml

17. Empson, W. (1930) .Seven Types of Ambiguity. $1^{\text {st }}$ edition. Oxford: Oxford University Press.

18. Empson, W. (2014). Seven Types of Ambiguity. $2^{\text {nd }}$ edition. Oxford: Oxford University Press.

19. Ferreira, V. S. (1996). Is it better to give than to donate? Syntactic flexibility in language production. Journal of memory and language, 35(5), 724-755. Retrieved from http://www.sciencedirect.com/science/article/pii/S0749596X9690038 8

20. Fraizer ,L. (1983). Against lexical generation of syntax. In W.Marslen-Wilson(Ed.), Lexical representation and process (pp. 505-528). Cambridge, MA: MIT Press.

21. Groebel, L. (1985). Ambiguity and second language learning. International Review of Applied Linguistics in Language Teaching (IRAL), 23(4). Retrieved from http://www.degruyter.com/view/j/iral.1985.23.issue-14/iral.1985.23.1-4.149/iral.1985.23.1-4.149.xml

22. Hayes, P. (1977). On Semantic nets frames and associations. Journal of verbal learning and verbal behavior, 13 (5). Retrieved from http://citeseerx.ist.psu.edu/doi=10.1.1.75.7429\&rep=rep1\&type=pdf

23. Hirst, G. (1987). Semantic Interpretation and Resolution of Ambiguity, Studies in Natural Language Processing. Artificial intelligence,34(2). Retrieved from http://www.sciencedirect.com/science/article/pii/0004370293900176

24. Hurford J. and Heasley B., (1983 ) Semantics: A Course Book. Cambridge: Cambridge University Press.

25. Karp, D.A. (1992). Illness Ambiguity and the search for meaning. A case study. Journal of Contemporary Ethnography, 21(2), 139-170. Retrieved from http/ jce.sagepub.com/

26. Kent, R. D. (1997). Gestural phonology: Basic concepts and applications in speech-language pathology. The new phonologies: Developments in clinical linguistics, 247-268.

27. Khalili, M., Rahmany, R., and Zarei, A. A. (2014). The effect of using gesture on resolving lexical ambiguity in L2. Journal of Language Teaching and Research, 5(5), 1139-1146. Retrieved from http://ojs.academypublisher.com/index.php/jltr/article/view/13275 
28. Khawalda, M., and Al-Saidat, M. (2012). Structural Ambiguity Interpretation: A Case Study of Arab Learners of English. Global Journal of Human-Social Science Research, 12(6). Retrieved from. http://socialscienceresearch.org/index.php/GJHSS/article/

29. Kimball, J. (1975). Predictive analysis and over-the-top parsing. Syntax and semantics, 4, 155-179. Retrieved from https://courses.cit.cornell.edu/ling7710/readings/KimballPredictive.p df

30. Klepousniotou, E. (2002). The processing of lexical ambiguity: Homonymy and polysemy in the mental lexicon. Brain and Language, 81(1), 205-223. Retrieved from http://www.sciencedirect.com/science/article/pii/S0093934X0192518 0

31. Kusumawati, D. (2001) The Study of Ambiguity in the articles of the Hello English magazine. Scientific Repository.v(89), 4-19 http://dewey.petra.ac.id/11547

32. Lappin, S., and Leass, H. (1994). An algorithm for pronominal anaphora resolution. Computational linguistics, 20(4), 535-561. Retrieved from http://dl.acm.org/citation.cfm?id=203989

33. Mayor, M. (2009). Longman dictionary of contemporary English. Pearson Education India.

34. Nezhad, Y., Atarodi, I., \& Khalili, M. (2013). Why on earth is learners' patience wearing thin: the interplay between ambiguity tolerance and reading comprehension valence of Iranian intermediate level students. Theory and Practice in Language Studies, 3(8), 1490. Retrieved from http://search.proquest.com/openview/900931d89d629c64e7e37fd4d0 80e978/1?pq-origsite=gscholar

35. Paget, R. (1930). Human Speech. Retrieved from http://doi.apa.org/?uid=1930-04942-000

36. Pehar, D. (2001). Use of ambiguities in peace agreements. Language and diplomacy, 163-200. Retrieved from http://www.diplomacy.edu/resources/general/use-ambiguities-peaceagreements

37. Salkind, N. (2012). Exploring Research. New York: Pearson.

38. Zelta, E.N. (2014). Ambiguity. In Stanford Encyclopedia of Philosophy. Retrieved from http://plato.stanford.edu. 


\section{Appendix A RECOGNITION LEVEL}

Underline the ambiguous part in each sentence.

1. The peasants are revolting.

2. The burglar threatened the student with the knife.

3. Adam loves his mother and so does Roy.

4. The young men and women are invited.

5. Eighteen people have slept in the new hotel's most expensive suite.

6. The fisherman went to the bank.

7. I saw her duck.

8. She is looking for a match.

9. Time flies like an arrow fruit flies like bananas.

10. There wasn't a single man at the party.

11. All men love a woman.

12. Every student thinks she is a genius.

13. All linguists prefer a theory.

14. Every student did not come on time.

15. All people have a national insurance number.

16. John and Mary are married.

17. He cooked her goose.

18. John ought to be at home right now.

19. Children make nutritious snack.

20. The statistician studied the whole year. 


\section{APPENDIX B}

Give all possible interpretations for the following sentences:

1. The professor said on Monday he would give an exam.

2. The police shot the rioters with guns.

3 . Look at the dog with one eye.

4. They are watching dogs.

5. Flying planes can be dangerous.

6. The American history teacher is very well educated.

7. Most doctors and parents trust Tylenol.

8. I hugged May and Rana and Mike saw me.

9. Eighteen people slept in the new hotel's most expensive suite.

10. Jake loves his mother more than Adam.

11. I know a richer man than Stevenson.

12. She looks more like her mother than her father.

13. She doesn't bear children.

14. I found the table fascinating.

15. There wasn't a single man at the party.

16. Sign in front of a vacant lot: "fine for littering."

17. She went to a weight loss clinic in London and lost 250 pounds.

18. The chicken is ready to eat.

19. He cooked her goose.

20. The statistician studied the whole year.

21. Children make nutritious snacks.

22. Mary and Jack are married.

23. There was a name tag near every plate.

24. A professor talked to each student.

25. All snakes are not poisonous.

26. Every man loves a woman.

27. Every student did not pass the exam.

28. The cops arrested the demonstrators because they were violent.

29. Mary asked Susan a question and she gave the answer.

30. John asked Peter because he likes him.

31. The school should assign the work description for the supervisors and teachers because they are overloaded.

32. Bob told Tom that a visitor was waiting for him.

33. I love you too.

34. John solved the problem too.

35. He only returned the assignment today.

36. I also have taken a tour to Paris.

37. She does not listen to her parents either.

38.Can you speak Spanish?

39. Can you call the police? 
40. Can you pass the salt shaker?

Sentences 1, 2, 3(syntactic attachment ambiguity) are adopted from (Zelta, 2014)

Sentences 4, 5, 6, (syntactic analytical ambiguity) are adopted from (Hirst, 1987)

Sentences 7, 8, 9, (syntactic coordination ambiguity) are adopted from (Cruse, 1986)

Sentences 10, 11, 12 , (syntactic elliptical ambiguity) are adopted from (Zelta, 2014), (Ferreira, 1996)

Sentences 13, 14, 15, 16, 17 (lexical ambiguity) are adopted from (Dayal, 2004)

Sentences 18, 19, 20, 21, 22 (semantic transformational ambiguity) are adopted from (Crystal ,1998) Cann, 1993

Sentences 23, 24, 25, 26, 27 ( semantic scope ambiguity) are adopted from (Zelta, 2014)

Sentences 28, 29, 30, 31, 32 are adopted from (Pehar,2001)

Sentence 33 is adopted from (Kent,1997)

Sentence 34, 35, 36, 37 are adopted from (Crystal, 1998)

Sentences 38, 39, 40 are adopted from (Empson,2014) .

\section{Appendix C \\ Production textual level}

Each of the following texts contains an ambiguity that hindered language processing. Explain.

1. "How is bread made?"

"I know that!" Alice cried eagerly. "You take some flour"

"Where do you pick the flower?" the white queen added. "In a garden or in the hedges?"

"Well, it isn’t picked at all”, Alice explained, "It is ground."

"How many acres of ground?" said the white queen?

Alice in Wonderland as cited in Zhang (2007)

2. "Mine is a long and sad tale", said the mouse turning to Alice and sighing.

"It is a long tail certainly", said Alice looking with wonder at the mouse's tail, "but why do you call it sad"?

Alice in Wonderland as cited in Zhang (2007)

3. "May I try on that two piece suit in the window?" asked the pretty young lady.

"Go right ahead", said the manager. "It might help business."

Hoke (1965, p.69)

4. "Jhonny, go over the road and see how old Mrs. Jones is." says the mother. 
The boy comes back to his mom "Mrs. Jones says it is none of my business."

(Gray ,2006)

5. "Hi Pete, what did you give your horse when he had the colic?"

"Turpentine", said Pete.

Thanks, said his friend.

Two weeks later they met again.

"Didn't you tell me, Pete, that you gave your horse turpentine when he had the colic?"

"Yes," said Pete.

"Well, I gave mine turpentine and he died."

"So did mine," said Pete.

(Misztal 1991, p.506) 